\title{
Connective Tissue Growth Factor (CTGF/CCN2) enhances lactogenic differentiation of mammary epithelial cells via integrin-mediated cell adhesion
}

\author{
Bethanie L Morrison ${ }^{1,2}$, Cynthia C Jose ${ }^{1}$, Mary Lou Cutler ${ }^{*}$
}

\begin{abstract}
Background: Connective Tissue Growth Factor (CTGF/CCN2), a known matrix-associated protein, is required for the lactogenic differentiation of mouse mammary epithelial cells. An HC11 mammary epithelial cell line expressing CTGF/CCN2 was constructed to dissect the cellular responses to CTGF/CCN2 that contribute to this differentiation program.

Results: Tetracycline-regulated expression of CTGF/CCN2 in HC11 cells enhanced multiple markers of lactogenic differentiation including $\beta$-casein transcription and mammosphere formation. In a separate measure of mammary differentiation the addition of CTGF/CCN2 to cultures of MCF10A cells increased the development of acini in vitro. In HC11 cells the elevated levels of CTGF/CCN2 diminished the requirement for extracellular matrix proteins in the activation of $\beta$-casein transcription, indicating that CTGF/CCN2 contributed to lactogenic differentiation through the regulation of matrix dependent cell adhesion. CTGF/CCN2 expression in HC11 cells increased expression of extracellular matrix proteins and integrins, enhanced the formation of focal adhesion complexes, and increased survival signaling. In addition, HC11 cells adhered to immobilized CTGF/CCN2 and this was inhibited by functionblocking antibodies to the integrins $\alpha 6$ and $\beta 1$, and to a lesser degree by antibody to $\beta 3$ integrin.

Conclusions: CTGF/CCN2 expression in HC11 cells led to an increase in multiple markers of lactogenic differentiation. The mechanisms by which CTGF/CCN2 contributed to lactogenic differentiation include direct binding of CTGF/CCN2 to integrin complexes and CTGF/CCN2-induced matrix protein expression resulting in elevated integrin functionality.
\end{abstract}

\section{Background}

The development of the mammary gland is hormonally regulated [1], but the actions of locally-derived growth factors and the interaction of mammary epithelial cells with their surrounding stroma are also critical factors for successful development [2]. Mammary epithelial cells interact with the extracellular matrix predominantly through the stromal components collagen and laminin [3-5]. Lactogenic differentiation is associated with the deposition of laminin-rich matrix by the epithelial cells $[6,7]$ and the degree of differentiation of mammary epithelial cells correlates with their response to basement membrane and stromal protein-induced signals. In addition, the production of milk proteins by the

\footnotetext{
* Correspondence: mcutler@usuhs.edu

'Department of Pathology, F. Edward Hebert School of Medicine, Uniformed Services University of the Health Sciences, Bethesda, MD 20814, USA
}

secretory epithelium is dependent on the presence of specific mitogens [8-10], cell-cell contact $[11,12]$, stimulation by the lactogenic hormone prolactin [13-15], and interaction with the extracellular matrix [7,16-18].

$\beta 1$ integrin expression is required for the survival of epithelial cells during differentiation [19] and it contributes to mammary gland development and morphogenesis $[20,21]$. The interaction of $\beta 1$ integrin with laminin is critical for the initiation of the transcription of the milk protein $\beta$-casein $[22,23]$. In addition, during lactogenic differentiation the activation of the prolactin receptor ultimately results in the translocation of phosphorylated Stat 5 dimers to the nucleus where they bind DNA and regulate transcription $[13,14,24]$, and integrinmediated adhesion is critical for the activation of Stat 5 [25]. In vitro studies of the interaction between mammary epithelial cells and basement membrane proteins 
during transcription of milk proteins recently implicated the $S W I / S N F$ transcription factor, Brg1, in translating signals from the stroma to the activation of the $\beta$-casein promoter [26].

Our previous work determined that Connective Tissue Growth Factor (CTGF/CCN2), a known stromal mediator, is highly up-regulated during the lactogenic differentiation of mouse mammary epithelial cells in a glucocorticoid-dependent response $[27,28]$. That study demonstrated that transient expression of CTGF/CCN2 enhanced $\beta$-casein transcription during the lactogenic differentiation of mouse mammary epithelial cells and that siRNA-mediated depletion of CTGF/CCN2 blocked the process [27]. CTGF/CCN2 is a member of the CCN family of matrix-associated proteins, which are known to be involved in processes including the regulation of growth, differentiation, migration and adhesion [29,30]. Members of the CCN family are comprised of 4 homology domains: the N-terminal insulin-like growth factor binding protein (IGFBP1) homology domain, followed by the von Willebrand C (VWC) repeat domain, the thrombospondin type 1 (TSP1) repeat domain, and the C-terminal cysteine knot (CT) domain [31]. CTGF/ $\mathrm{CCN} 2$ is known to interact with $\beta 1$ integrin complexes through its TSP1 and C-terminal domains [32,33]. Because functional $\beta 1$ integrin complexes are required for lactogenesis in vivo and in vitro, our studies focused on the effect of CTGF/CCN2 expression on this axis in mammary epithelial cells.

The studies presented here employed HC11 mouse mammary epithelial cells, a cell line capable of lactogenic differentiation in vitro [34-36], that has been used in our previous studies $[27,37,38]$. HC11 cells are non-transformed, immortalized, and undergo lactogenic differentiation upon stimulation with dexamethasone, insulin and prolactin [34,39]. To address the mechanism by which CTGF/CCN2 contributes to the regulation of lactogenic differentiation, CTGF/CCN2 was expressed under the control of a Tetracyclineregulated promoter in $\mathrm{HC} 11$ cells. The results confirm and extend our previous findings that CTGF/CCN2 mediates the enhancement of multiple markers of lactogenic differentiation in $\mathrm{HC} 11$ cells [27]. In addition, ectopic expression of CTGF/CCN2 increased the formation of focal adhesion complexes, integrin-mediated survival signaling and cell adhesion. Hence, these findings suggest that CTGF/CCN2 acts to stabilize the cell-matrix interactions required for cell survival by multiple mechanisms, and this translates directly and indirectly into enhanced lactogenic differentiation as measured by the subsequent phenotypic changes and the transcription of $\beta$-casein.

\section{Results \\ Ectopic CTGF/CCN2 expression enhanced the lactogenic differentiation of $\mathrm{HC} 11$ cells}

Previous studies conducted in our laboratory demonstrated that CTGF/CCN2 was transcriptionally regulated by the glucorticoid dexamethasone during the induction of lactogenic differentiation in HC11 cells, and that elevated CTGF/CCN2 expression was required for the differentiation program [27]. To elucidate the mechanism by which CTGF/CCN2 enhances the lactogenic differentiation of mammary epithelial cells, a stable HC11-based cell line was created by employing inducible expression of CTGF/CCN2 under the control of a Tet-responsive promoter (TRE). Analysis of these cells revealed that the expression of vector-encoded $\mathrm{CTGF} / \mathrm{CCN} 2$ readily increased following the removal of doxycycline from the culture media [27]. Following induction of CTGF/CCN2 expression in $\mathrm{HC} 11$ cells its effect on lactogenic differentiation was evaluated by the addition of the lactogenic hormone mixture of dexamethasone, insulin, and prolactin (DIP) to the cultures. Known markers of lactogenic differentiation, including $\beta$-casein transcription and mammosphere formation, were analyzed.

The formation of domed structures called mammospheres occurs during lactogenic differentiation of HC11 cells in culture and serves as a phenotypic marker of this process $[40,41]$. The effect of CTGF/CCN2 expression on mammosphere formation was examined following stimulation of HC11-TRE-CTGF and the vector control HC11-TRE cells with DIP for five days. The HC11-TRE-CTGF cells displayed enhanced mammosphere formation, both in the size (Figure 1A) and number (Figure 1B), compared to the identically treated vector control cells.

The transcription of the milk protein $\beta$-casein is a marker of lactogenic differentiation. Our previous studies demonstrated that transient expression of CTGF in HC11 cells enhanced $\beta$-casein transcription compared to control cells [27]. Hence, confluent cultures of HC11TRE-CTGF and HC11-TRE cells were stimulated with lactogenic hormone and assayed for differentiation by following $\beta$-casein transcription. Because endogenous CTGF/CCN2 is rapidly induced by dexamethasone, a component of the lactogenic hormone mix, the expression of $\beta$-casein RNA was examined in untreated cells and prior to 24 hours of DIP treatment. At 0 and 8 hours post DIP stimulation the effect of vector-encoded CTGF/CCN2 on this process (Figure 1C) was detected. The results indicated a higher level of $\beta$-casein transcription at 8 hours in the HC11-TRE-CTGF cells compared to the HC11-TRE cells, confirming that CTGF/ $\mathrm{CCN} 2$ expression enhances transcription of $\beta$-casein in 


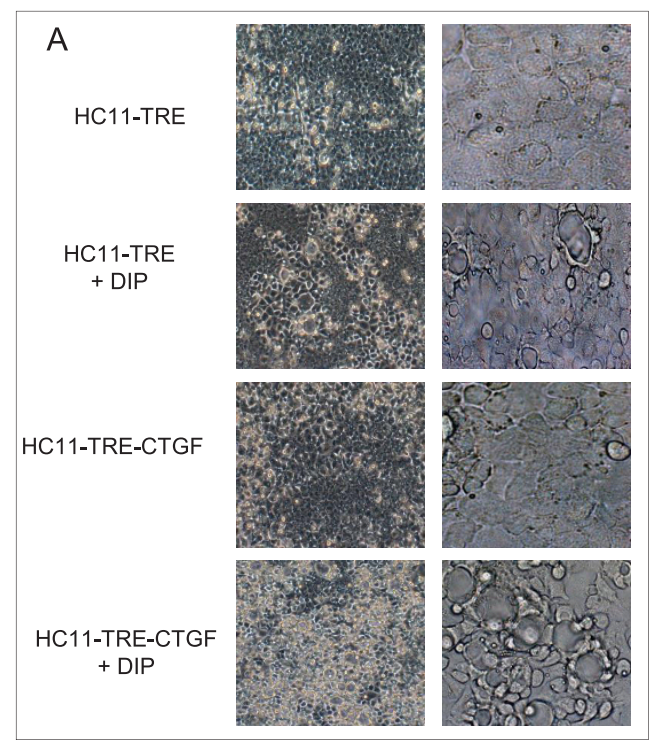

B

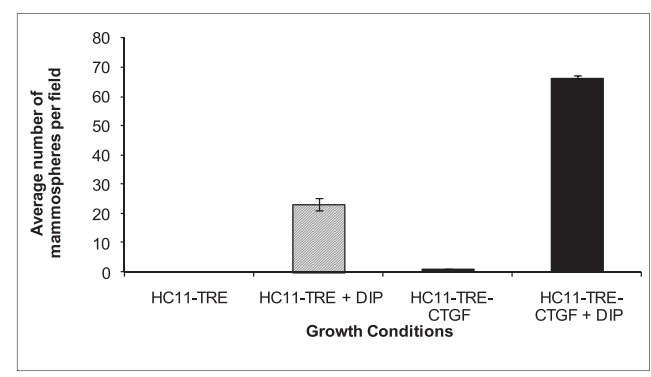

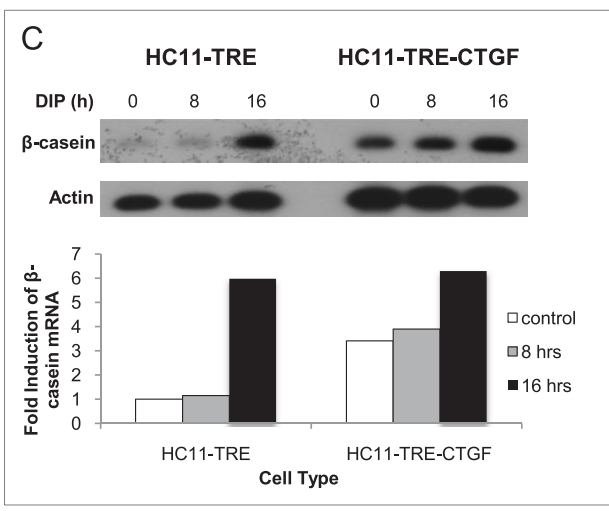

D

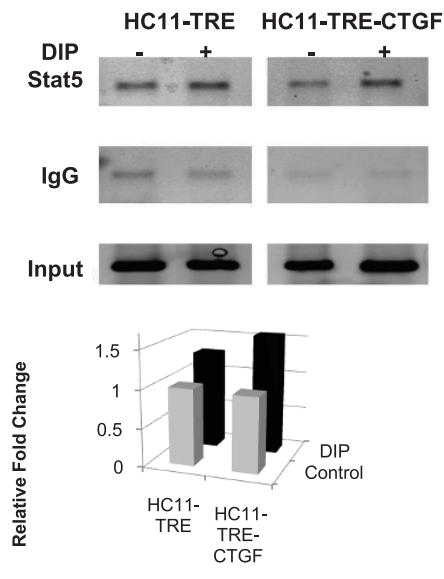

E
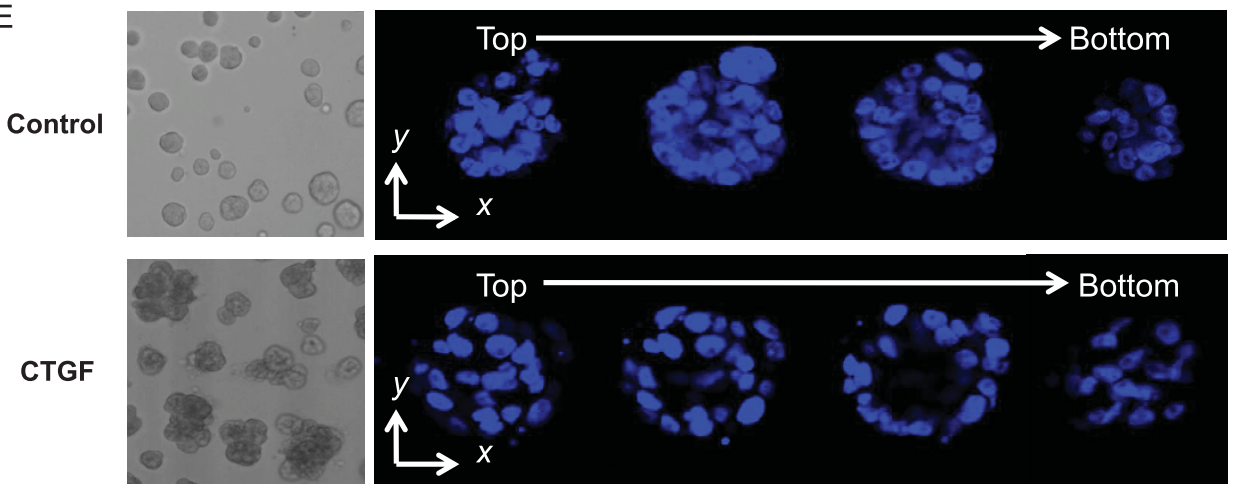

Figure 1 Ectopic CTGF/CCN2 expression in HC11 cells enhances lactogenic differentiation. (A) HC11-TRE and HC11-TRE-CTGF cells were grown to confluence and exposed to DIP. The cells were photographed at $120 \mathrm{hrs}$ post-DIP addition and are shown at 20x and 40X magnification. The images shown representative of five fields. Mammospheres are bubble-like structures. (B) Mean is the result of the average number of mammospheres in five low power microscopic fields. Data is expressed as the mean + S.D. (C) HC11-TRE and HC11-TRE-CTGF cells were stimulated with DIP for 0,8 , or 16 hours. RNA was extracted and examined by Southern blotting. For quantitation, expression levels of $\beta$ casein were normalized to actin and expressed as a fold induction of $\beta$-casein mRNA compared to the HC11-TRE control. (D) Chromatin immunoprecipitation analysis of $\beta$-casein promoter. HC11-TRE and HC11-TRE-CTGF cells were grown in serum-free media for 24 hours prior to being induced with DIP for 16 hours. (Top) PCR analysis of DNA immunoprecipitated with either an anti-Stat5 antibody or control IgG using primers to amplify the $\beta$-casein promotor. (Bottom) Graphical analysis of PCR results from DNA immunoprecipitated with an anti-Stat5 antibody, normalized to the amount of input DNA. Light columns = no DIP, dark columns = DIP (E) CTGF/CCN2 enhances the number and formation of MCF-10A acini in Matrigel. MCF-10A cells were suspended in Matrigel and seeded on Matrigel in 8 well chamber slides. Cells were grown in the absence or presence of CTGF/CCN2 $(50 \mathrm{ng} / \mathrm{ml})$ for 20 days. Images in depict acinar structures in culture by phase contrast microscopy at magnificantion 10x. The cells were fixed and the nuclei stained with DAPI. Shown are serial confocal cross sections of acinar structures with respect to the $Z$ axis. The sequential sections reveal the hollow lumen (magnification 20x). 
the HC11 cell line. In addition, the Tet-regulated CTGF/CCN2 expression resulted in low but detectable $\beta$-casein in the absence of added lactogens $(T=0)$ suggesting that a low level of lactogenic hormone, presumably contributed by serum in the media, could induce $\beta$-casein transcription in the presence of CTGF/CCN2.

The contribution of CTGF/CCN2 to $\beta$-casein promoter activation was assessed by evaluating the binding of Stat 5 to the $\beta$-casein promoter via a chromatin immunoprecipitation assay (ChIP). Stimulation of HC11 cells with prolactin activates Jak 2 resulting in Stat 5 phosphorylation, dimerization, nuclear translocation and DNA binding. Control and CTGF-expressing HC11 cells were stimulated with the lactogenic hormone mix for 24 hours. The treated cells were fixed in formaldehyde, the nuclei were isolated and sonicated, and Stat5-DNA complexes were recovered by immunoprecipitation. The $\beta$-casein proximal promoter was amplified from the purified recovered DNA in order to determine the level of Stat5 DNA binding. Results, shown in Figure 1D, revealed that elevated CTGF/CCN2 expression led to a modest but reproducible increase in the binding of Stat 5 on the $\beta$-casein proximal promoter in the induced but not the unstimulated cells. In repeated experiments $(\mathrm{N}$ $=5$ ) the outcome ranged from 1.25-2.1 fold greater binding in TRE-CTGF than the TRE control cells. The fact that detection of Stat5 promoter binding required extended DIP-stimulation (i.e. 24 hours) diminished the differences between the control and CTGF/CCN2expressing cells that were observed at the level of $\beta$ casein RNA. However, this result supported the finding of increased $\beta$-casein transcription in CTGF/CCN2expressing cells.

\section{CTGF/CCN2 increased acinar formation by MCF10A cells}

The formation of polarized acini-like spheroids that mimic aspects of the architecture of the mammary gland in vivo is a marker of differentiation for the immortalized human mammary epithelial cell line MCF10A [42]. The MCF10A cells form spheroids on Matrigel and this is followed by apoptosis-driven clearing of the lumen of these structures. The formation and differentiation of the spheroids relies on integrin engagement for the orientation and polarization of the cells to form three dimensional structures. Because CTGF/CCN2 expression enhanced the formation of the HC11 cell domed mammospheres, the effect of CTGF/ $\mathrm{CCN} 2$ on the formation of the acinar structures by MCF10A cells was examined. CTGF/CCN2 was supplied to the MCF10A cells exogenously in a purified and soluble form. In this assay MCF10A cells were suspended in Matrigel in the presence or absence of CTGF/CCN2 and overlayed onto a solidified layer of Matrigel. The cultures were maintained for 20 days, at which time the cells were fixed, stained and analyzed by confocal microscopy. The images, shown in Figure 1E, depict individual DAPI-stained acinar structures in the presence or absence of CTGF/CCN2 as sections from top to bottom of the acinus. Initially, the presence of CTGF/CCN2 in the media enhanced both the size and the number of the spheroid structures formed by the MCF10A cells. However, over time the MCF10A cells cultured in the presence of CTGF/CCN2 also exhibited a high level of differentiation. This was characterized by a structured epithelial cell layer surrounding a hollow lumen. Thus, CTGF/CCN2 influenced the growth and differentiation of both HC11 mouse mammary epithelial cells in twodimensional culture as well as MCF10A mammary epithelial cells in three-dimensional culture.

\section{CTGF/CCN2 functioned via matrix interaction during $\beta$-casein transcription in $\mathrm{HC} 11$ cells}

Previous studies have shown that CTGF/CCN2 acts as a stromal mediator by binding to integrins and other components of the extracellular matrix $[43,44]$, and the activation of $\beta 1$ integrin complexes by matrix components is required for $\beta$-casein transcription and lactogenic differentiation [45]. Therefore, the effect of CTGF/ $\mathrm{CCN} 2$ on extracellular matrix regulation of $\beta$-casein transcription was examined. HC11-TRE-CTGF and vector control cells were seeded on fibronectin-, collagen I, or Matrigel-coated or uncoated tissue culture dishes. Following stimulation of the cells with lactogenic hormone, RNA was extracted and used to analyze $\beta$-casein expression by northern blot. Results are shown as the fold induction of $\beta$-casein transcription in each cell line grown on matrix proteins compared to the level of transcription on plastic (Figure 2). The results demonstrated a greater than 3 -fold increase in $\beta$-casein transcription in HC11-TRE vector control cells exposed to extracellular matrix components compared to tissue culture plastic. In contrast, HC11-TRE-CTGF cells did not display a significant increase of $\beta$-casein transcription when grown on fibronectin, collagen I or Matrigel. Thus, it appears that ectopic expression of CTGF/CCN2 partially abrogates the influence of matrix components required to initiate $\beta$-casein transcription. Moreover, the results suggest that CTGF/CCN2 contributes significantly to the collagen and laminin receptor engagement which is required for the initiation of HC11 mammary epithelial cell differentiation and $\beta$-casein transcription.

\section{CTGF/CCN2 stimulation contributed to $\mathrm{HC} 11$ cell proliferation and survival}

CTGF/CCN2 increased mitogenesis in numerous types of cells. Previously published data from our lab demonstrated that elevated expression of CTGF/CCN2 in HC11 cells resulted in enhanced expression of $\beta 1$ 


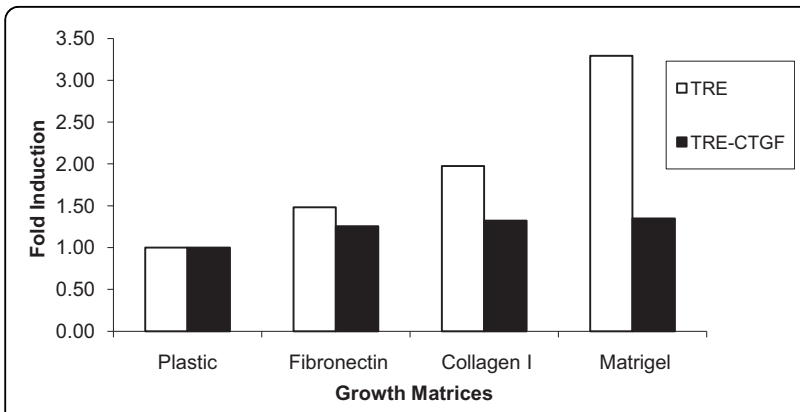

Figure 2 CTGF/CCN2 contributes to the epithelial-matrix interaction during lactogenic differentiation in $\mathrm{HC} 11$ cells. HC11-TRE and HC11-TRE-CTGF cells were seeded in serum-free conditions on respective coated or uncoated tissue culture dishes and once confluent, induced to differentiate with DIP for 48 hours. Total RNA was harvested and levels of $\beta$-casein transcript were determined by northern blot analysis and normalized to actin. Contribution of the matrix proteins to $\beta$-casein transcription can be seen by fold induction analysis of the RNA (white bars = HC11-TRE, dark bars $=$ HC11-TRE-CTGF).

integrin and the activation of focal adhesion kinase (FAK) [27]. Thus, to determine the contribution of CTGF/CCN2 to integrin-mediated processes that effect the growth of $\mathrm{HC} 11$ cells, CTGF/CCN2-expressing HC11 cells were compared to vector control cells for proliferative capacity in the absence of serum. The proliferation was determined by MTT assay (Figure 3A) and the results indicated HC11-TRE-CTGF cells displayed significantly more proliferative capacity than the HC11-TRE vector control cells. In particular, proliferation was sustained by CTGF/CCN2 expression at later times when the $\mathrm{HC} 11$ vector control cells ceased proliferation.

CTGF/CCN2 is a secreted protein and approximately half of the CTGF produced by the HC11-TRE-CTGF cells is found in the media [27]. Therefore, conditioned media from HC11-TRE-CTGF cells was harvested and also used to determine the effect of CTGF/CCN2 on the growth of HC11 cells. Results, shown in Figure 3B, indicated that CTGF/CCN2-conditioned media sustained the growth of $\mathrm{HC} 11$ cells longer than conditioned media from HC11-TRE cells. Again, the most significant differences were observed at later time points. Together with the effect of endogenously produced CTGF/CCN2, these results suggest that CTGF/CCN2 played a role in the proliferation of cells especially in the absence of serum. However, neither $\mathrm{HC} 11$ vector control, nor $\mathrm{HC} 11$ cells expressing or treated with CTGF/CCN2, proliferated in the absence of EGF (data not shown). This indicated that the effect(s) of CTGF/CCN2 in the HC11 cells differed from those of EGF on the same cells.

The apparent ability of CTGF/CCN2 to facilitate integrin-mediated processes and proliferation, suggested a

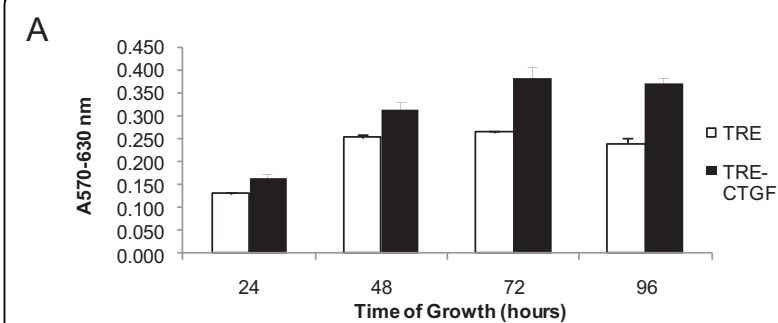

B

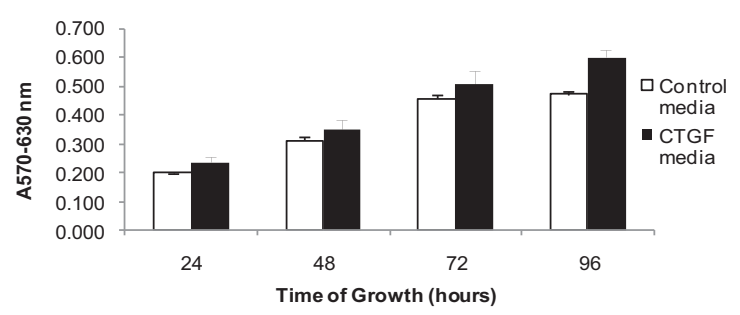

Figure 3 CTGF/CCN2 stimulation contributes to HC11 cell proliferation. (A) HC11-TRE and HC11-TRE-CTGF cells were seeded in 96-well microtiter plates in serum-free media with EGF (10 ng/ ml). (B) HC11 cells were seeded in serum-free media with EGF (10 $\mathrm{ng} / \mathrm{ml}$ ) plus serum-free conditioned media from HC11-TRE or HC11TRE-CTGF (1:1 ratio). Cell proliferation was determined at 24, 48, 72, and 96 hours post addition of EGF using the MTT assay. The results are reported as the mean + S.D. of four determinations. *, $p<0.005$.

role for $\mathrm{CTGF} / \mathrm{CCN} 2$ in sustaining the survival of $\mathrm{HC} 11$ cells. Therefore, the effect of CTGF/CCN2 expression on the ability of $\mathrm{HC} 11$ cells to progress through the cell cycle in the absence of serum was examined. HC11-TRE and HC11-TRE-CTGF cells were harvested following 96 hours in serum-free media, stained with propidium iodide (PI) and analyzed by flow cytometry. Figure 4A contains a cell cycle analysis comparison of the HC11TRE and HC11-TRE-CTGF cell lines. The data in Figure $4 \mathrm{~B}$ indicate the percentage of total HC11-TRE and HC11-TRE-CTGF cell populations in the sub $G_{0} / G_{1}, G_{1}$, $S$, and $G_{2} / M$ phases of the cell cycle. In each cell line the majority of cells were in the $G_{1}$ phase of the cell cycle, however, in support of the data suggesting sustained growth of HC11 cells by CTGF/CCN2, the cells expressing CTGF/CCN2 had greater percentage of the population in both $S$ and $G_{2} / M$ phases. In contrast, the HC11-TRE vector control cells showed a greater population of cells in sub $G_{0} / G_{1}$, which is indicative of possible apoptosis. To determine the level of apoptosis, the cells were examined for TUNEL, a measure of DNA fragmentation characteristic of cells undergoing apoptosis. The results, shown in Figures 4C, indicated a higher level of TUNEL staining in HC11-TRE cells compared to the HC11-TRE-CTGF cells.

Because CTGF/CCN2 enhanced the survival of HC11 cells, the contribution of CTGF/CCN2 to the activation 
A
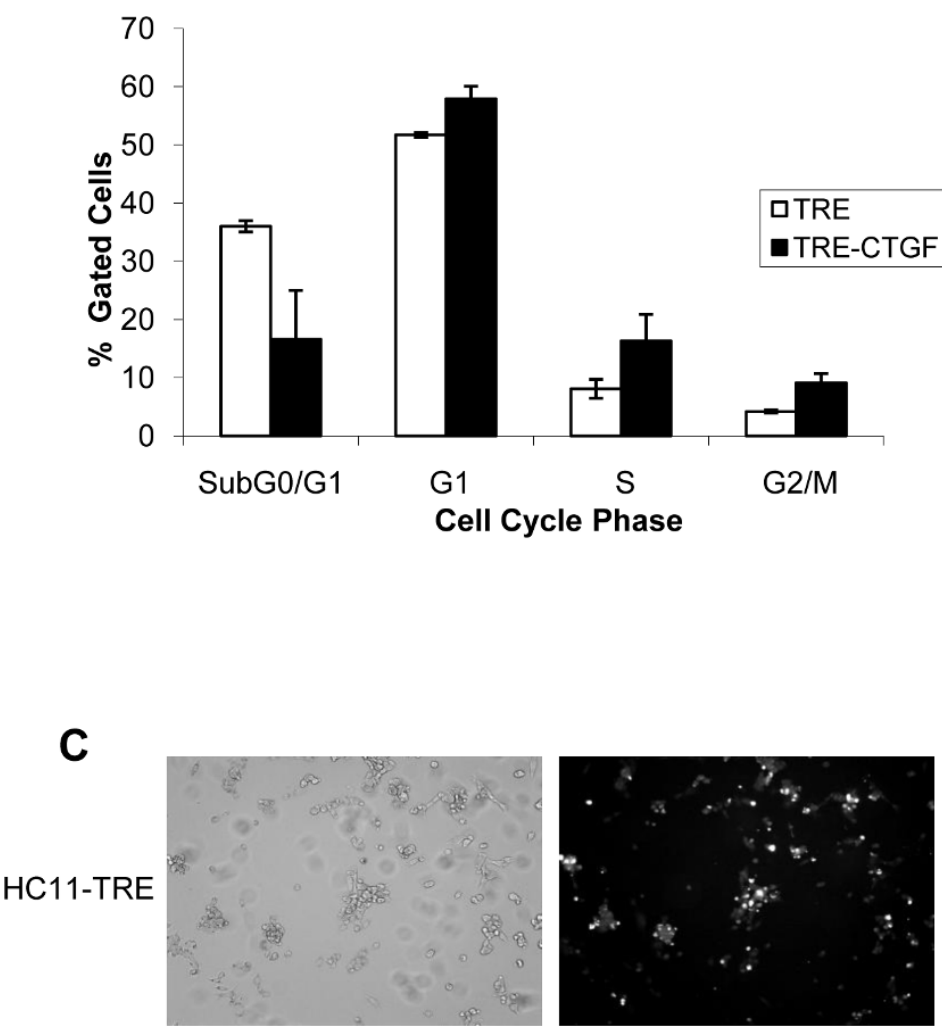

HC11-TRECTGF
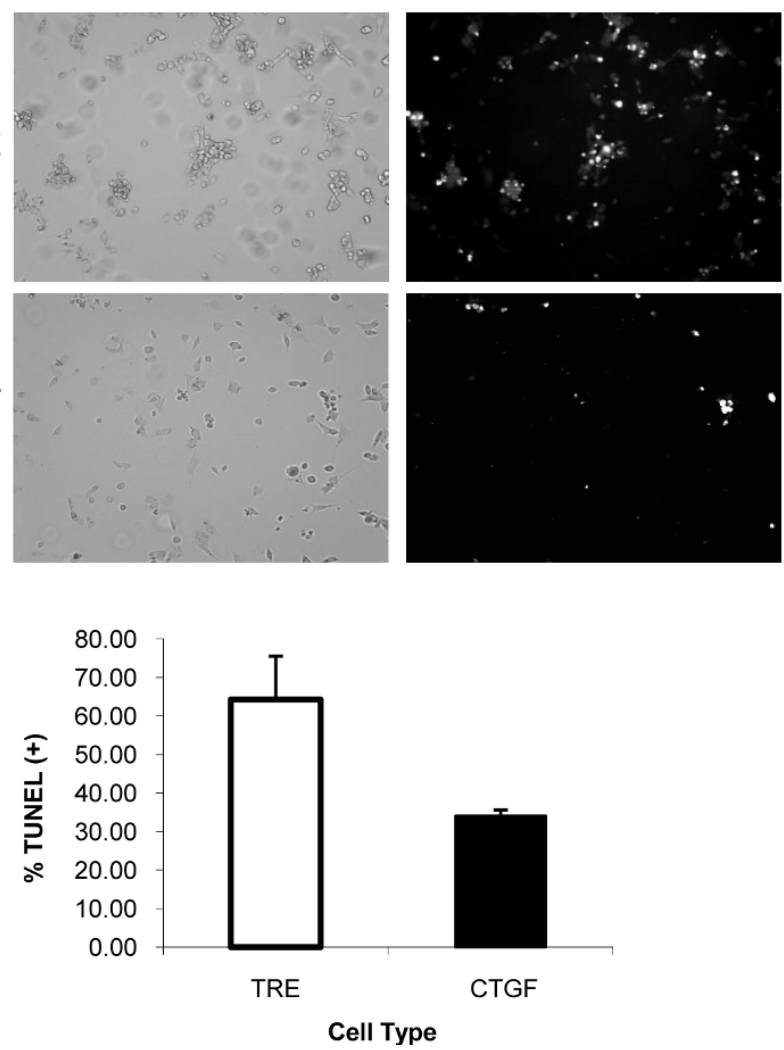

B
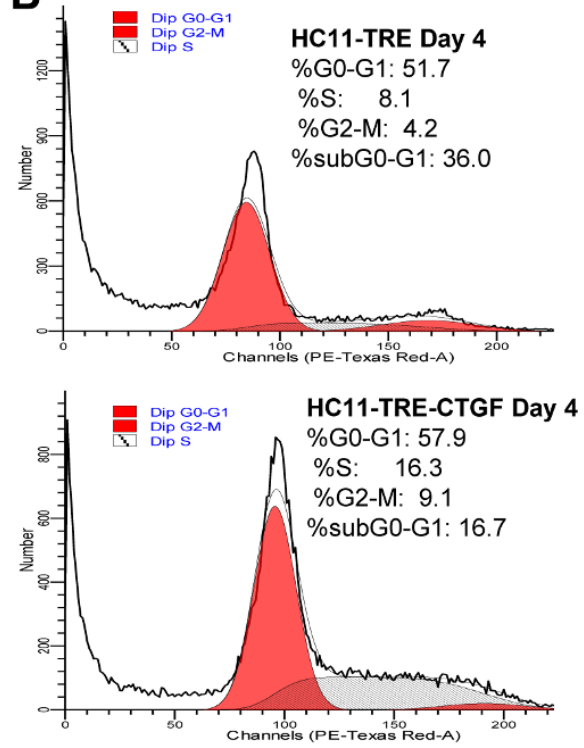

D
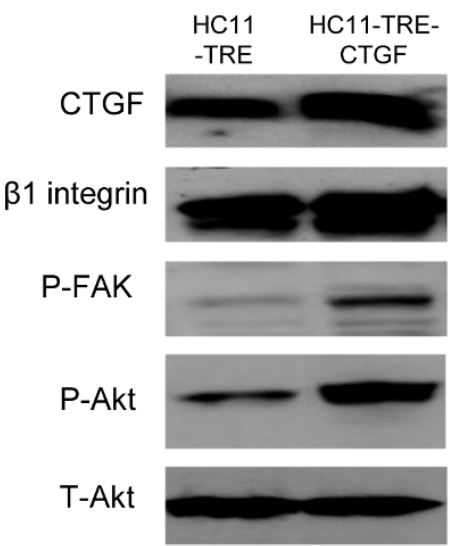

Cyclin D1

$\mathrm{BCl}-\mathrm{xL}$

Actin
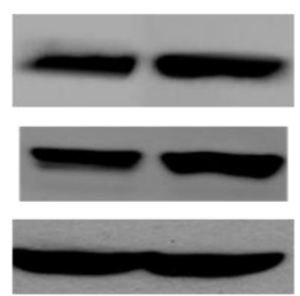

Figure 4 CTGF/CCN2 sustains the survival of mammary epithelial cells. (A) HC11-TRE and HC11-TRE-CTGF cells were seeded in serum-free media in the presence of EGF $(10 \mathrm{ng} / \mathrm{ml})$ and harvested after 96 hours. Cells were fixed in ethanol and stained with propidium iodide $(50 \mu \mathrm{g} /$ $\mathrm{ml}$ ) prior to cell cycle analysis by flow cytometry. Data is representative of three determinations. Percentage of total gated cells in each phase of the cell cycle is shown. (B) Graphical analysis of cell cycle distribution by DNA content in HC11-TRE cells or in HC11-TRE-CTGF cells. (C) HC11-TRE and HC11-TRE-CTGF cells were seeded on coverslips in serum-free media in the presence of EGF $(10 \mathrm{ng} / \mathrm{ml})$ for 96 hours, then fixed and apoptosis was detected by TUNEL. Left panels depict cell morphology, while the panels on the right display positive TUNEL staining in white. Quantification of TUNEL staining is shown in panel below. (D) HC11-TRE and HC11-TRE-CTGF cells were seeded in serum-free media with EGF $(10 \mathrm{ng} / \mathrm{ml})$. Lysates were harvested after 96 hours and the expression levels of the indicated survival proteins was analyzed by western blot. Results are representative of 3 experiments. 
of integrin-mediated survival signaling was examined. Protein lysates from HC11-TRE-CTGF and HC11-TRE vector control cells were collected after 96 hours in serum-free media and used to determine the expression of mediators of integrin adhesion and survival signaling (Figure 4D). The results indicated that HC11-TRECTGF cells display enhanced expression of $\beta 1$ integrin, phosphorylated FAK, phosphorylated Akt, Bcl-xL and cyclin D1 compared to expression levels in HC11-TRE cells. The level of $\beta 3$ integrin was slightly increased in the CTGF-expressing cells as well (data not shown). These results indicated that CTGF/CCN2 contributed to integrin-mediated survival signaling in mammary epithelial cells and implicated the $\beta 1$-containing integrin complex(es) in the control of both proliferation and survival of $\mathrm{HC} 11$ cells.

\section{CTGF/CCN2 increased integrin expression and function in HC11 cells}

CTGF/CCN2 bound to and enhanced the expression of $\beta 1$ integrin in other cell types $[27,46]$, and the activation of $\beta 1$ integrin signaling is required for $\beta$-casein transcription [47]. Hence, the degree to which the CTGF/CCN2mediated effects on cell proliferation and survival were dependent on the CTGF/CCN2-induced integrin activation was tested. An MTT assay was performed in the presence of an integrin-binding RGD-containing peptide that would be expected to act as a competitive inhibitor for $\beta 1$ integrin complexes including $\alpha \mathrm{V} \beta 1$ and $\alpha 5 \beta 1$, as well as $\alpha$ V $\beta 3$. HC11-TRE and HC11-TRE-CTGF cells were seeded in serum-free conditions with or without the RGD peptide or control RAD peptide. Levels of proliferation were determined by MTT assay. Results, shown in Figure 5A, displayed the expected enhanced proliferation trend of HC11-TRE-CTGF cells compared to the vector control HC11-TRE cells. The HC11-TRE-CTGF cells incubated with the RGD peptide exhibited a $38 \%$ reduction in proliferative capacity at 96 hours, whereas the RAD peptide showed no effect on the CTGF/CCN2enhanced proliferation of the cells. In contrast, the RGD peptide inhibited growth of the TRE cells by 7\% during the same time period. Hence, while the control cells express some endogenous levels of CTGF/CCN2, it is the elevated expression of CTGF/CCN2 that provides a cell adhesion and survival advantage, and targeting those functions exposes the dependence on CTGF/CCN2 in the TRE-CTGF cell line. These results suggested that the RGD peptide partially blocked the integrin engagement that occurred as a result of CTGF/CCN2 expression, thereby affecting growth and survival.

CTGF/CCN2 interacts with the $\alpha 6 \beta 1$ integrin complex in other cell types. $\alpha 6 \beta 1$ integrin is a common mammary epithelial cell receptor for laminin [17] and $\beta 1$ is critical for mammary gland development in vivo and milk protein synthesis in cultured mammary epithelial cells $[20,48]$. To evaluate the effect of CTGF/CCN2 on the levels of expression of these integrins, HC11TRE and HC11-TRE-CTGF cells were incubated with antibodies against surface level $\alpha 6$ or $\beta 1$ integrin and analyzed by flow cytometry. Results, shown in Figure $5 \mathrm{~B}$, indicated that $\mathrm{HC} 11-\mathrm{TRE}-\mathrm{CTGF}$ cells displayed a greater level of both $\alpha 6$ and $\beta 1$ integrin on their surface compared to the HC11-TRE control cells. Together these results suggested that CTGF/CCN2 enhanced proliferation and survival signaling through the stabilization and activation of an $\alpha 6 \beta 1$ integrin complex or other $\alpha 6$ and $\beta 1$ containing complexes.

\section{HC11 cell adhesion to CTGF/CCN2 required integrin complexes}

CTGF/CCN2 is a secreted, integrin binding molecule. To determine if CTGF/CCN2 was acting to mediate cell adhesion, the ability of $\mathrm{HC} 11$ cells to attach to either control or CTGF/CCN2-coated plates was tested. HC11-TRE control cells were allowed to attach to recombinant CTGF/CCN2-coated microtiter wells for 4 hours. Adherent cells were fixed and stained and the absorbance at $570 \mathrm{~nm}$ was determined for quantitation of cell adhesion. A significant increase in the adhesion of cells seeded on CTGF/CCN2-coated wells was observed compared with cells seeded on the BSA-coated control wells (Figure 6A). The adhesion was inhibited by the inclusion of EDTA, and rescued with the addition of $\mathrm{Mg}^{2+}$, indicative of the interaction required for CTGF/CCN2-integrin-mediated attachments [49].

To determine if the $\alpha 6 \beta 1$ integrin complex was involved in the CTGF/CCN2-mediated enhancement of adhesion, the adhesion assay was performed in the presence of function blocking antibodies against both $\alpha 6$ and $\beta 1$ integrins. CTGF/CCN2 also binds $\alpha \mathrm{V} \beta 3$ so function blocking antibodies against $\alpha \mathrm{v}$ and $\beta 3$ integrins were tested as well (Figure 6B). The addition of the anti- $\alpha 6$ or anti- $\beta 1$ antibodies completely blocked the CTGF/CCN2-mediated increase in adhesion while the addition of the anti- $\beta 3$ showed less inhibition, and the anti- $\alpha \mathrm{V}$ or isotype control antibodies showed no significant change in CTGF/CCN2-mediated adhesion. Together with the flow cytometry data demonstrating the CTGF/CCN2-mediated enhancement of surface level expression of the $\alpha 6 \beta 1$ integrin complex, these results confirmed the involvement of the $\alpha 6 \beta 1$ integrin complex in the CTGF/CCN2-mediated increase in HC11 cell adhesion.

\section{CTGF/CCN2 expressing cells displayed increased formation of focal adhesions}

Interactions between mammary epithelial cells and the basement membrane are crucial for survival. To further 


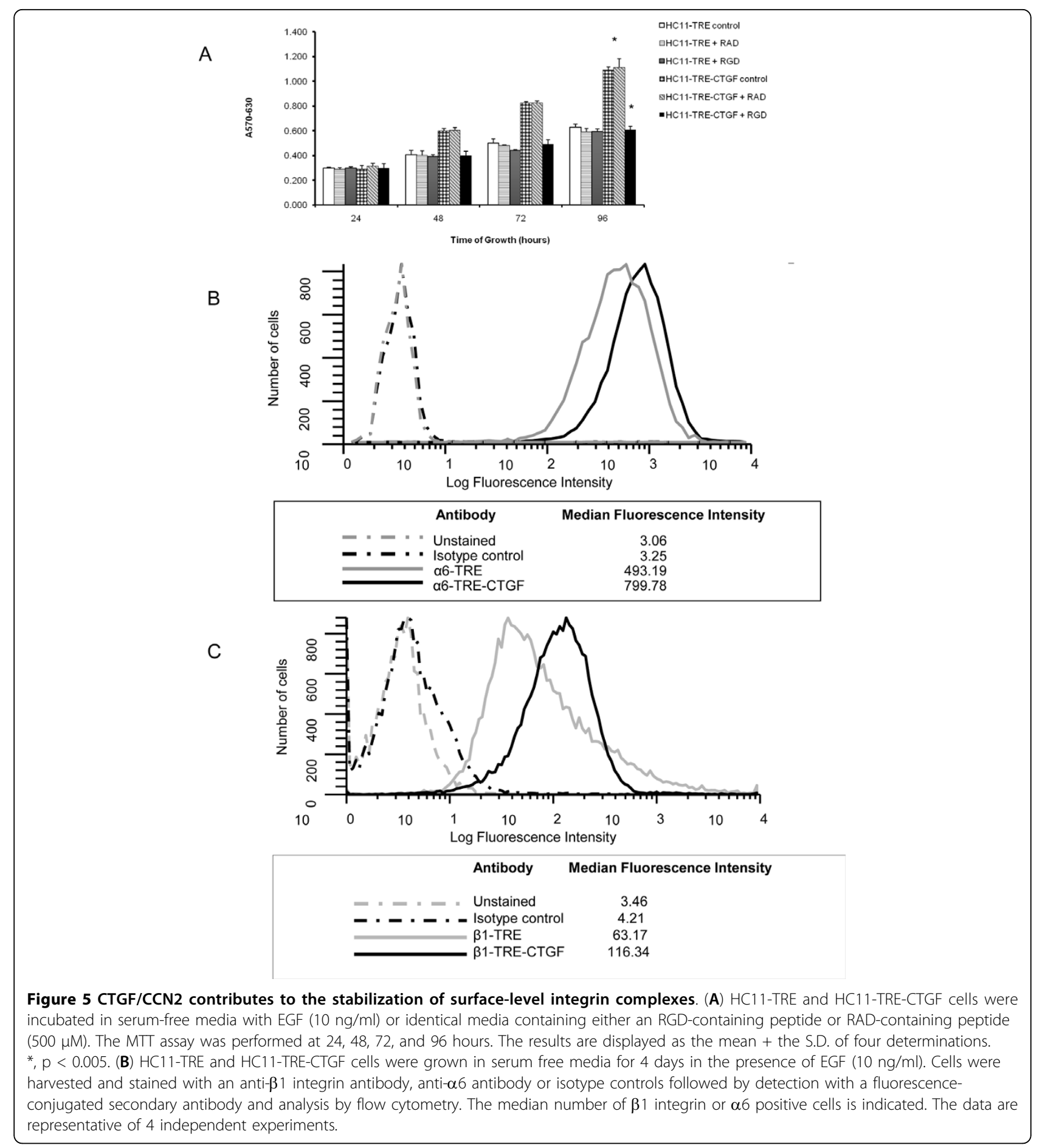

understand the effects of CTGF/CCN2 elevation and stabilization of $\beta 1$ integrin complexes on the formation of focal adhesion complexes, the level and the appearance of focal adhesion and extracellular matrix proteins were analyzed. Protein lysates from HC11-TRE and HC11-TRE-CTGF cells were used for determination of specific protein expression by western blot (Figure 7A).
Results revealed increases in the focal adhesion-associated adaptor and structural proteins in HC11-TRECTGF cells including paxillin, p130CAS, vinculin, parvin, PINCH1, and Rsu-1 [50]. Furthermore, HC11TRE-CTGF cells displayed increases in Src but not integrin linked kinase (ILK). Elevated transcription of collagen, laminin and fibronectin was detected in $\mathrm{HC} 11$ 


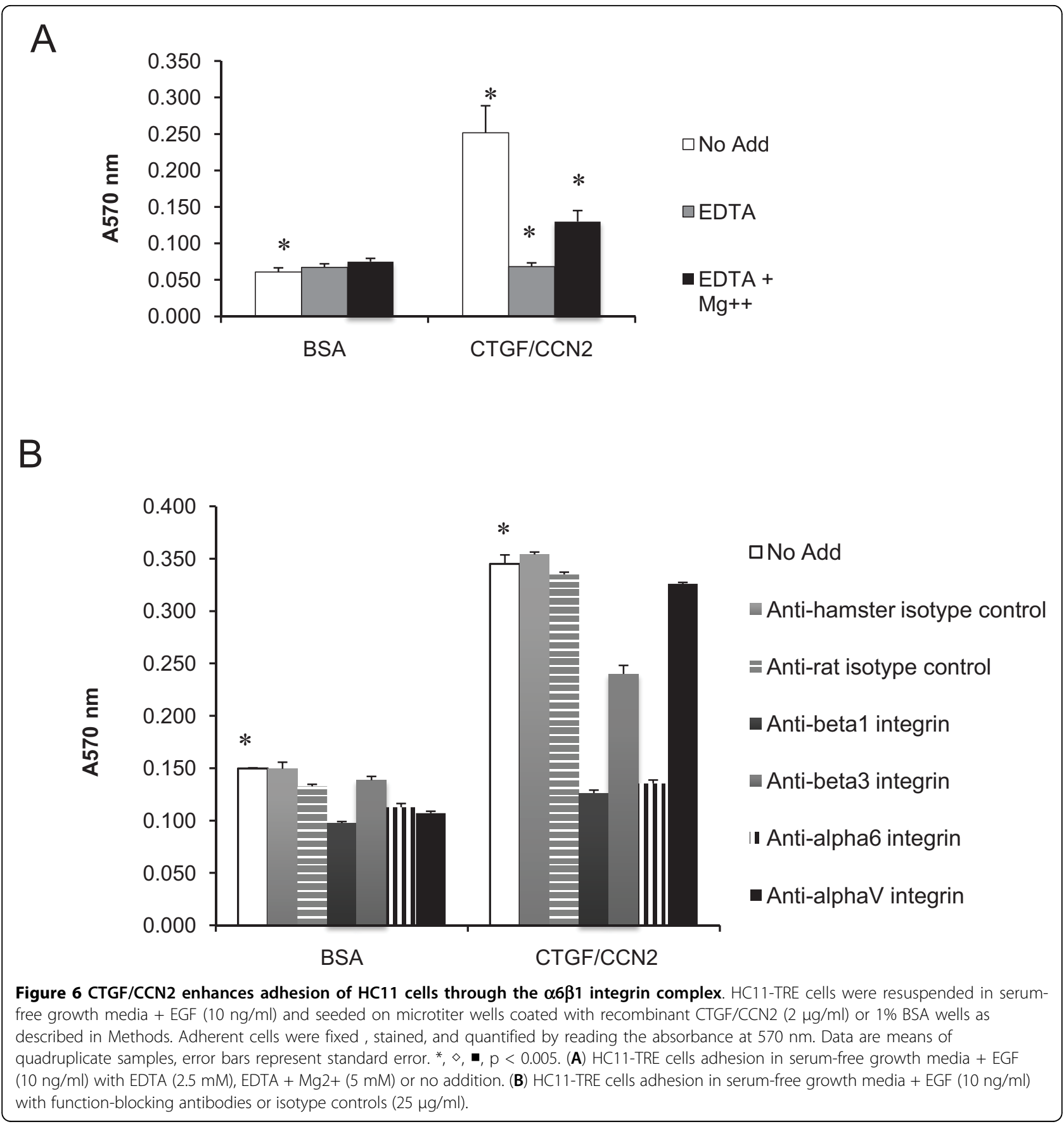

TRE-CTGF cells compared to the TRE control cell line (data not shown) and elevated fibronectin was detected in HC11-TRE-CTGF cells by western blot (Figure 7B). Immunofluorescent staining of the cells with an antibody to vinculin revealed greater focal adhesion formation, both in size and number, in HC11-TRE-CTGF cells compared to vector control HC11-TRE cells (Figure 7B), demonstrating the functionality of CTGF/ $\mathrm{CCN} 2$ on integrin-dependent formation of focal adhesions in HC11 mammary epithelial cells.
In conclusion, these results indicated that the mechanism by which CTGF/CCN2 contributed to lactogenic differentiation was via activation of integrin-mediated adhesion complex(es), particularly the $\alpha 6 \beta 1$ complex, which enhanced cell adhesion and survival in HC11 cells. This could be attributed to direct binding of CTGF/CCN2 to integrin complexes and to CTGF/ $\mathrm{CCN} 2$-induced laminin and fibronectin expression. Both events would be expected to result in elevated integrin expression and functionality. Because the engagement of 


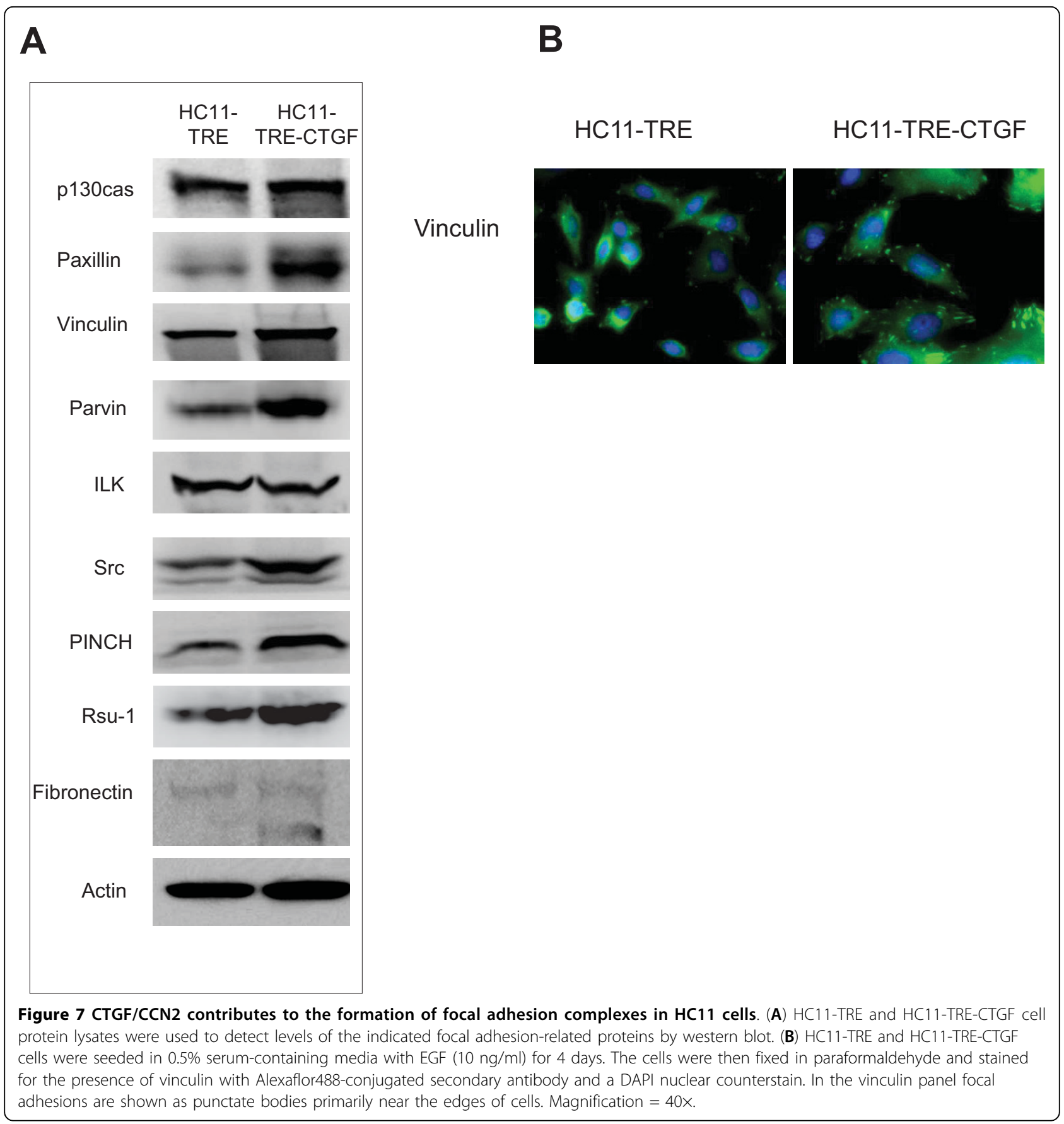

$\beta 1$ integrin is required for the transcription of $\beta$-casein and lactogenic differentiation of the mammary gland, these results suggest an important role for CTGF/CCN2 in mammary epithelial cell function.

\section{Discussion and Conclusions}

Stromal mediators play a fundamental role in promoting mammary differentiation, and the contact between mammary epithelial cells and components of the basement membrane contributes to the prolactin-induced transcription of milk proteins [47]. Using the Tet-off system for inducible CTGF/CCN2 expression in the HC11 mouse mammary epithelial cell background, CTGF/CCN2 not only enhanced the early transcription of $\beta$-casein in response to lactogenic hormone, but also contributed to the formation of mammospheres, a hallmark of terminal differentiation in these cells. In addition, exogenous CTGF/CCN2 enhanced the formation of differentiated MCF10A acini in three dimensional cultures, extending the role of CTGF/CCN2 to another 
culture system which is likely to be structurally and physiologically relevant to the in vivo setting [42]. The role of CTGF/CCN2 in lactogenic differentiation may depend on its function in the expression and stabilization of matrix-integrin complexes, an activity which promotes prolactin-induced Stat 5 activity.

The data reported here suggest that CTGF/CCN2 increased expression of fibronectin and laminin and stabilized the surface expression of the $\alpha 6$ and $\beta 1$ integrins. Typically, epithelial cells lose their ability to survive in the absence of serum and detach, initiating an apoptotic process called anoikis. However, CTGF/CCN2 served as a survival mediator thereby preventing $\mathrm{HC} 11$ cells from undergoing apoptosis in the absence of serum. The binding of integrins to matrix proteins promotes conformational changes in the extracellular domains of the integrins and a subsequent clustering of integrins in focal adhesions. Survival signaling resulting from the formation of focal adhesion complexes involves p130cas, paxillin, ILK, and Src [51]. The complex is formed after adhesion-induced phosphorylation of FAK-Y397. Recruitment of Src causes tyrosine phosphorylation of additional sites on FAK, and FAK-mediated phosphorylation of p130cas and paxillin [52]. FAK activation may also contribute to cell survival by direct activation of the P-I-3 kinase/Akt pathway [53]. CTGF/CCN2 expression correlated with enhanced expression levels of the major proteins involved in the focal adhesions referred to above, as well as PINCH1 and Rsu-1, which localize to focal adhesion complexes [54,55]. Anti-vinculin immunofluorescence visualized larger focal adhesions in CTGF/CCN2-expressing cells compared to control HC11 cells. These results confirm a role for CTGF/ CCN2 in the stabilization of active integrin-mediated complexes and adhesion-activated survival signaling. This is likely linked to the CTGF/CCN2-mediated adhesion signaling via integrins and the activation of Akt and expression of Bcl-xL. However, HC11 cells expressing CTGF/CCN2 also exhibited elevated levels of Map kinase phosphatase1 (MKP-1) (data not shown), a dual specificity phosphatase frequently induced in response to Map Kinase signaling. MKP-1 dephosphorylates p38 kinase, suggesting that preventing the accumulation of phospho-p38 may be a contributing mechanism by which CTGF/CCN2 inhibits apoptosis.

CTGF/CCN2-mediated activation of $\beta 1$ integrin signaling has been demonstrated in primary skin fibroblasts [56] and activated pancreatic stellate cells [46]. In fibroblasts CTGF/CCN2 also induced expression of the extracellular matrix proteins laminin, collagen, fibronectin and integrin subunits [57], similar to the increase in these proteins that was observed in the $\mathrm{HC} 11$ cells engineered to express CTGF/CCN2. The elevated expression of fibronectin and laminin would be expected to the increase integrin engagement and focal adhesion formation. Moreover, Cyr61/CCN1 and Nov3/CCN3, highly homologous members of the $\mathrm{CCN}$ family, have been shown to bind to and enhance $\beta 1$ integrin-mediated functions in primary skin fibroblasts $[49,58]$. In our study enhanced integrin-dependent signaling may have resulted from direct interaction between integrins and secreted or cell-bound CTGF/CCN2, as suggested by the integrin blocking antibody data in Figure 6. In addition, the elevation of matrix protein expression may have increased RGD-binding integrin engagement in HC11 cells and this likely contributed to enhanced proliferation and survival of HC11 TRE-CTGF cells in the absence of serum. Another contribution may result from elevation of syndecan 4, a heparin sulfate proteoglycan, which has been reported to stabilize integrin complexes, including $\beta 1$ integrin complexes [59]. Syndecan 4 upregulation has been observed in CTGF/CCN2-stimulated or -expressing cells $[60,61]$, and the HC11-TRE-CTGF cells also express elevated levels of syndecan 4 compared to the HC11-TRE vector control cell line (data not shown).

The association of mammary epithelial cells with laminin is critical for the activation and the nuclear translocation of Stat5 [25]. Association of the cells with the matrix proteins occurs through active binding to $\beta 1$ integrin complexes on the cell surface. It is known that binding to laminin via the $\beta 1$ integrin complex [3] is directly associated with the induction of lactogenesis and $\beta$-casein transcription [5], although the $\alpha$ integrin has not been definitely identified [62,21]. Our data indicate that CTGF/CCN2 enhances the expression of laminin resulting in decreased requirement for exogenous laminin in the activation of $\beta$-casein transcription, as seen in Figure 2. CTGF/CCN2 expressing cells did not display the same laminin-dependent increase in the level of $\beta$-casein mRNA as control cells, suggesting that CTGF/CCN2 partially abrogates the requirement for those proteins for the transcription of $\beta$-casein. Collectively, these results suggest that the mechanism by which CTGF/CCN2 enhances lactogenic differentiation is through enhancement and stabilization of the laminin- $\alpha 6 \beta 1$ integrin cell-matrix interaction that is required early in the lactogenic differentiation process.

The adhesion of epithelial cells to extracellular matrix initiates signaling mechanisms that control cell proliferation, survival, and differentiation throughout the phases of mammary gland development. Our finding that ectopic expression of CTGF/CCN2 enhanced the growth and survival of $\mathrm{HC} 11$ cells in vitro supports a proposed role for CTGF/CCN2 during late pregnancy and early lactation, a period when CTGF/CCN2 levels are elevated in vivo $[27,28]$. While this study focused on the mechanism of CTGF/CCN2 in HC11 mouse mammary epithelial 
cells, CTGF/CCN2 also enhanced the transcription of $\beta$ casein in primary mouse mammary epithelial cells stimulated to differentiate [27]. Recent mammary specific knockdown studies ascertained that $\beta 1$ integrin as well as FAK and Src contribute to the development of the mammary gland and the induction of lactogenesis $[22,63,64]$. Mammary specific inhibition of $\beta 1$ integrin reduced the activation of the MAPK and Akt and ultimately resulted in diminished mammary growth and increased mammary developmental defects $[20,63]$. Similarly, a mammary specific knockout of FAK caused tissue defects as well as a reduction in milk protein production; this was attributed to a diminished secretory capacity of the epithelium due to the combination of decreased proliferative ability and a lack of Stat5 activation [22]. Moreover, a knockout of Src blocked lactational ability of the mammary gland although the gland maintained otherwise normal growth [64]. Based on the results reported here, the effects of a mammary specific knock down of CTGF/CCN2 may prove useful in understanding the control of lactogenic differentiation in vivo.

\section{Methods}

Cell culture and the construction of CTGF Tet-off cell line HC11 mouse mammary epithelial cells, provided by Dr. Nancy Hynes, were maintained in RPMI 1640 medium supplemented with $10 \%$ fetal bovine serum, $5 \mu \mathrm{g} / \mathrm{ml}$ insulin, $10 \mathrm{mM}$ HEPES and $10 \mathrm{ng} / \mathrm{ml} \mathrm{EGF}$ as described $[13,35]$. The HC11 cell line containing the pTet-Off plasmid (Clontech, Mountainview, CA) was infected with a pREV-TRE (Clontech) retroviral vector encoding epitope-tagged CTGF/CCN2 and used to express HACTGF/CCN2 in response to removal of doxycycline (Dox) as described previously [27]. The HC11-TRE vector control cells and HC11-TRE-CTGF cells were grown in doxycycline $(2 \mu \mathrm{M})$ which was removed for 96 hours to induce CTGF/CCN2 expression for experiments.

Prior to stimulation with lactogenic hormones, HC11 cells and HC11-derived cell lines were grown to confluence and maintained for 3-5 days to establish competence $[9,39]$ then maintained in media without EGF for 24 hours. To induce lactogenic hormone-induced differentiation, the cells were rinsed twice and then incubated in differentiation media, RPMI with dexamethasone $\left(10^{-6} \mathrm{M}\right), 5 \mu \mathrm{g} / \mathrm{ml}$ insulin, and $10 \mu \mathrm{g} / \mathrm{ml}$ prolactin, referred to as DIP. Lactogenic differentiation was characterized by analysis of $\beta$-casein transcription and by the formation of domed structures referred to as mammospheres, which were visualized by phase contrast microscopy and manually enumerated.

\section{MCF10A acinus formation}

Acinus formation was performed with MCF10A cells using an established technique with minor modifications
[42]. Growth factor reduced Matrigel was added to wells of an eight-well glass chamber slide. Basement membrane was allowed to solidify for 15 minutes at $37^{\circ} \mathrm{C}$. MCF-10A cells were harvested, washed in DMEM/F12, $2 \%$ horse serum and resuspended in assay media (DMEM/F12, 2\% horse serum, $0.5 \mu \mathrm{g} / \mathrm{ml}$ hydrocortisone, $100 \mathrm{ng} / \mathrm{ml}$ cholera toxin, $10 \mu \mathrm{g} / \mathrm{ml}$ insulin). A mixture of assay media containing EGF $(20 \mathrm{ng} / \mathrm{ml})$ plus $4 \%$ Matrigel was prepared with or without CTGF/CCN2 (25-100 $\mathrm{ng} / \mathrm{ml}$, Cell Sciences, Canton, MA). A 1:1 mixture of the Matrigel-containing assay media and MCF-10A cells $(25,000$ cells $/ \mathrm{ml})$ was plated on top of the solidified basement membrane. The cells were incubated at $37^{\circ} \mathrm{C}$ for 20 days with media changes every 4 days. Each well was fixed with $2 \%$ paraformaldehyde followed by permeabilization in $0.5 \%$ Triton $\mathrm{X}-100$ at $4^{\circ} \mathrm{C}$. Wells were then rinsed with PBS containing glycine $(100 \mathrm{mM})$ and blocked with IF buffer $(7.7 \mathrm{mM}$ sodium azide, $0.1 \%$ BSA, 0.2\% Triton X-100, 0.05\% Tween-20, 10\% FBS). The cells were washed in PBS and mounted to slides with ProLong Gold antifade reagent containing DAPI (Molecular Probes, Invitrogen, Eugene, OR). Confocal imaging was performed on a Zeiss Pascal Laser Scanning Confocal Microscope (Carl Zeiss, Thornwood, NY).

\section{RNA isolation, RT-PCR, northern blotting, and Southern blotting}

Total RNA was isolated and purified using the TriPure reagent (Roche, Palo Alto, CA). Northern blots were prepared with $10 \mu \mathrm{g}$ of total RNA separated on a $1 \%$ agaroseformaldehyde gel and transferred to a nylon filter. Reverse transcriptase PCR (RT-PCR) was performed using the GeneAmp RNA PCR Kit and primers for $\beta$-casein amplification as follows: Fwd 5' CATCCTTTCAGCTTCACC, Rev 5' AGAGACAGCTGgGtCTGAG. Primers for mouse $\beta$-actin were as follows: Fwd 5' CTAAGGCCAACCGTGAAAAGA, Rev 5' GAGGTCTTTACGGATGTCAAC. PCR products were electophoresed on a $1 \%$ agarose gel. The DNA was denatured and neutralized and transferred to a nylon filter. Northern and Southern blots were hybridized as described previously [27]. The probes for CTGF, $\beta$-casein and actin have been described $[27,37]$.

\section{Chromatin Immunoprecipitation}

Confluent HC11-TRE and HC11-TRE-CTGF cells were stimulated with DIP for 16 hours prior to cross-linking with $1 \%$ formaldehyde for 10 minutes at room temperature, followed by treatment with $1.12 \mathrm{ml}$ of $2.5 \mathrm{M}$ glycine for 5 minutes at room temperature. The precipitating antibodies used included anti-rabbit IgG (Chemicon, PP64) or anti-Stat5 N-term (Santa Cruz, sc836). Primers for the $\beta$-casein proximal promoter, forward 5'CCAGCTTCTGAATTGCTGCC3', reverse 
5' GGTCTATCAGACTCTGTGAC3', were used in PCR reactions of 35 cycles of 1 minute at $95^{\circ} \mathrm{C}, 30$ seconds at $55^{\circ} \mathrm{C}, 30$ seconds at $72^{\circ} \mathrm{C}$. Amplified DNA was analyzed by electrophoresis on an ethidium bromide stained 1.5\% agarose gel. Bands were quantitated using the Fujifilm LAS-4000 (Fujifilm Medical Systems USA, Inc.). Results are expressed as a ratio of immunoprecipitated DNA to the input DNA.

\section{Western blotting and Immunoprecipitation}

The procedures for western blotting have been described $[27,37,38,55]$. The antibodies used in this study include: mouse anti- $\beta$-actin (Sigma, St. Louis, MO), goat anti-CTGF (Santa Cruz Biotechnology, Santa Cruz, CA), mouse anti- $\beta 1$ integrin (BD Transduction, BD Biosciences, San Diego, CA), mouse anti-FAK (BD Transduction), rabbit anti-phospho-FAK (Upstate Technologies), rabbit anti-Akt (Cell Signaling Technolgies, Danvers, MA ), rabbit anti-phospho-Akt (Cell Signaling Technology), rabbit anti-Bcl-xL (Santa Cruz Biotechnology), mouse anti-PINCH1 (BD Transduction), rabbit anti-ILK (Santa Cruz Biotechnology), rabbit anti-actopaxin/parvin (Sigma), mouse anti-p130CAS (Upstate Technologies), mouse anti-paxillin (BD Transduction), rabbit anti-c-src (Santa Cruz Biotechnology), mouse anti-vinculin (Sigma). The rabbit anti-Rsu-1 antibody has been described [55].

\section{Immunofluorescence}

To detect focal adhesions, HC11-TRE and HC11-TRECTGF cells were grown in the absence of doxycycline for 4 days, at which time they were seeded on coverslips and maintained in serum-free media + EGF $(10 \mathrm{ng} / \mathrm{ml})$ for 4 days. The cells were washed with PBS, fixed in $4 \%$ paraformaldehyde then permeabilized with $0.5 \%$ Triton $\mathrm{X}-100$ and blocked in $4 \%$ BSA prior to an overnight incubation at $4^{\circ} \mathrm{C}$ with an anti-vinculin antibody (Sigma). Coverslips were washed with PBS and incubated for 30 minutes in the dark at room temperature with an AlexaFluor 488-conjugated secondary antibody then mounted with ProLong Gold antifade reagent containing DAPI (Molecular Probes, Invitrogen, Eugene, OR). Immunofluorescence was visualized using an Olympus IX71 microscope, a QImaging Retiga 2000RV camera, and QCapture Pro 6.0 software (Olympus America Inc, Center Valley, PA).

\section{MTT and TUNEL Assays}

Proliferation of HC11-TRE-CTGF and vector control HC11-TRE cells was determined by MTT assay (CellTiter96 Assay, Promega, Madison, WI). Viable cells grown in the absence of doxycycline for 96 hours were replated at a density of $1.5 \times 10^{4}$ per well in quadruplicate wells of a 96-well plate in serum-free media with EGF $(10 \mathrm{ng} / \mathrm{ml})$.
HC11-TRE cells were analyzed following exposure to conditioned media from HC11-TRE-CTGF cells, and in the presence of RGD- or RAD-containing peptide (500 $\mu \mathrm{M}$, BioMol, Plymouth Meeting, PA). The cells were incubated for 24, 48, 72, or 96 hours. Analysis of the MTT assay has been described previously [37].

Apoptosis was detected in vector control HC11-TRE cells and HC11-TRE-CTGF cells by TUNEL technology (In Situ Cell Death Detection Kit, Fluorescein, Roche). Cells previously grown in the absence of doxycycline for 96 hours were grown on coverslips in serum-free media in the presence of EGF $(10 \mathrm{ng} / \mathrm{ml})$ for 96 hours. The cells were fixed in $4 \%$ paraformaldehyde, permeabilized in $0.1 \%$ Triton X-100 on ice, and rinsed in PBS and incubated in $50 \mu \mathrm{l}$ TUNEL reagent for 1 hour at $37^{\circ} \mathrm{C}$ in the dark. The cells were rinsed in PBS prior to being mounted on slides (Vectashield mounting media, Vector Labs, Burlingame, CA). Cells were viewed on the Olympus BX61 and analyzed by IVision software (IVision, Atlanta, GA).

\section{Flow cytometry}

Cell cycle analysis and surface level expression of $\alpha 6$ and $\beta 1$ integrins were determined by flow cytometry. HC11TRE and HC11-TRE-CTGF cells grown without doxycycline for 96 hours were propagated for 96 hours in serumfree media with EGF $(10 \mathrm{ng} / \mathrm{ml})$. The cells were harvested with Cell Stripper (Mediatech, Manassas, VA), pelleted, washed, and counted. For cell cycle analysis, cells were resuspended in PBS and methanol was added dropwise for fixation prior to storage at $-20^{\circ} \mathrm{C}$ for $24-96$ hours. The cells were pelleted and resuspended in cold PBS and propidium iodide $(50 \mu \mathrm{g} / \mathrm{ml})$ was added to the cells prior to flow cytometric analysis. For integrin expression analysis, the cells were aliquoted into $1 \mathrm{ml}$ samples of 500,000 cells each and washed in FACS wash buffer (1\% FBS, 0.05\% sodium azide). Cells were then incubated in buffer with antibodies against $\beta 1$ integrin (BD Biosciences) or $\alpha 6$ integrin (BD Biosciences) or the isotype controls for 1 hour at $4^{\circ} \mathrm{C}$ then pelleted and resuspended FACS buffer containing PE- or FITC- conjugated secondary antibodies for 45 minutes at $4^{\circ} \mathrm{C}$. The cells were fixed in Cytofix (BD Biosciences) on ice, washed and resuspended in FACS buffer. All flow cytometry was performed using a BD Biosciences LSRII cytometer. Cell cycle analysis was performed using ModFit LT software and integrin expression analysis was performed using WinList software (Verity Software House Inc.).

\section{CTGF/CCN2 adhesion assay}

To determine the interaction between CTGF/CCN2 and integrin complexes, HC11-TRE cells were seeded in serum-free media + EGF $(10 \mathrm{ng} / \mathrm{ml})$ on maleic anhydride Reacti-Bind microtiter wells (Thermo 
Scientific, Rockville, MD) coated with recombinant CCN2 protein (Cell Sciences, Canton, MA). The plates were coated with CTGF/CCN2 $(2 \mu \mathrm{g} / \mathrm{ml})$ overnight at $4^{\circ} \mathrm{C}$, followed by blocking with $1 \%$ BSA for 2 hours at $37^{\circ} \mathrm{C}$. HC11-TRE cells were suspended at a concentration of $5 \times 10^{5}$ cells $/ \mathrm{ml}$, and where indicated mixed with EDTA $(2.5 \mathrm{mM})$, EDTA $(2.5 \mathrm{mM})+\mathrm{Mg}^{2+}$, blocking antibodies to $\alpha \mathrm{V}, \beta 3$ (Santa Cruz Biotechnologies), $\alpha 6$, or $\beta 1$ integrins (BD Biosciences), or isotype control antibodies. Cells were allowed to attach for 4 hours at $37^{\circ} \mathrm{C}$, washed gently with $\mathrm{PBS}$ and fixed with $3.7 \%$ formaldehyde for 10 minutes at room temperature. Fixed cells were washed with stained with crystal violet and the adherent cells were quantified by reading the absorbance at $570 \mathrm{~nm}$.

\section{Abbreviations \\ CTGF: Connective Tissue Growth Factor; FAK: Focal Adhesion Kinase; RGD: Arginine-Glycine-Aspartic Acid; RAD: Arginine-Alanine-Aspartic Acid}

\section{Acknowledgements}

This work was supported by grants from the CDMRP (DAMD-17-01-0264) and the United States Military Cancer Institute to M.L. Cutler.

The authors are grateful to Dr. Nicholas Kenney for helpful discussions.

\section{Author details}

'Department of Pathology, F. Edward Hebert School of Medicine, Uniformed Services University of the Health Sciences, Bethesda, MD 20814, USA. ${ }^{2}$ Current Address: Drug Mechanism Group - Developmental Therapeutics Program, SAIC Frederick/NCI-FCRDC, Bldg. 320, Rm 8, Frederick, MD 21702, USA.

\section{Authors' contributions}

BM performed differentiation experiments, expression studies, binding assays, immunofluorescence and flow cytometry and drafted the manuscript. CJ performed some western blots, RNA isolation and northern blots. MLC conceived of the project, participated in its design and coordination and prepared the final draft of the manuscript. All authors read and approved the final manuscript.

\section{Competing interests}

The authors declare that they have no competing interests and that the funding agencies did not influence the design of the project or the preparation of the manuscript.

Received: 29 December 2009 Accepted: 24 May 2010 Published: 24 May 2010

\section{References}

1. Wood BG, Washburn LL, Mukherjee AS, Banerjee MR: Hormonal regulation of lobulo-alveolar growth, functional differentiation and regression of whole mouse mammary gland in organ culture. J Endocrinol 1975, 65(1):1-6.

2. Medina D: The mammary gland: a unique organ for the study of development and tumorigenesis. J Mammary Gland Biol Neoplasia 1996, 1(1):5-19.

3. Mercurio AM: Laminin receptors: achieving specificity through cooperation. Trends Cell Biol 1995, 5(11):419-423.

4. Woodward TL, Mienaltowski AS, Modi RR, Bennett JM, Haslam SZ: Fibronectin and the alpha(5)beta(1) integrin are under developmental and ovarian steroid regulation in the normal mouse mammary gland. Endocrinology 2001, 142(7):3214-3222.

5. Roskelley CD, Srebrow A, Bissell MJ: A hierarchy of ECM-mediated signalling regulates tissue-specific gene expression. Curr Opin Cell Biol 1995, 7(5):736-747
6. Myers CA, Schmidhauser C, Mellentin-Michelotti J, Fragoso G, Roskelley CD, Casperson G, Mossi R, Pujuguet P, Hager G, Bissell MJ: Characterization of $B C E-1$, a transcriptional enhancer regulated by prolactin and extracellular matrix and modulated by the state of histone acetylation. Molecular and Cellular Biology 1998, 18(4):2184-2195.

7. Li ML, Aggeler J, Farson DA, Hatier C, Hassell J, Bissell MJ: Influence of a reconstituted basement membrane and its components on casein gene expression and secretion in mouse mammary epithelial cells. Proceedings of the National Academy of Sciences of the United States of America 1987, 84(1):136-140.

8. Taketani Y, Oka T: Tumor promoter 12-O-tetradecanoylphorbol 13acetate, like epidermal growth factor, stimulates cell proliferation and inhibits differentiation of mouse mammary epithelial cells in culture. Proceedings of the National Academy of Sciences of the United States of America 1983, 80(6):1646-1649.

9. Taverna D, Groner B, Hynes NE: Epidermal growth factor receptor, platelet-derived growth factor receptor, and c-erbB-2 receptor activation all promote growth but have distinctive effects upon mouse mammary epithelial cell differentiation. Cell Growth Differ 1991, 2(3):145-154.

10. Merlo G, Grause-Porta D, Cella N, Marte B, Taverna D, Hynes N: Growth, differentiation and survival of HC11 mammary epithelial cells: diverse effects of receptor tyrosine kinase-activating peptide growth factors. European Journal of Cell Biology 1996, 70:97-105.

11. Brisken C, Ayyannan A, Nguyen C, Heineman A, Reinhardt F, Tan J, Dey SK, Dotto GP, Weinberg RA: IGF-2 is a mediator of prolactin-induced morphogenesis in the breast. Developmental Cell 2002, 3(6):877-887.

12. Nguyen DA, Parlow AF, Neville MC: Hormonal regulation of tight junction closure in the mouse mammary epithelium during the transition from pregnancy to lactation. J Endocrinol 2001, 170(2):347-356.

13. Marte B, Jeschke M, Grause-Porta D, Taverna D, Hofer P, Groner B, Yarden Y, Hynes N: Neu differentiaiton factor/heregulin modulates growth and differentitaion of HC11 mammary epithelial cells. Molecular Endocrinology 1995, 9:14-23.

14. Gouilleux F, Wakao H, Mundt M, Groner B: Prolactin induces phosphorylation of Tyr694 of Stat5 (MGF), a prerequisite for DNA binding and induction of transcription. The EMBO Journal 1994, 13(18):4361-4369.

15. Han Y, Watling D, Rogers N, Stark G: Jak2 and Stat5, but not Jak1 and Stat1, are required for prolactin-induced beta-lactoglobulin transcription. Molecular Endocrinology 1997, 11:1180-1188.

16. Delcommenne $\mathrm{M}$, Streuli $\mathrm{CH}$ : Control of integrin expression by extracellular matrix. The Journal of Biological Chemistry 1995, 270(45):26794-26801.

17. Klinowska TC, Soriano JV, Edwards GM, Oliver JM, Valentijn AJ, Montesano R, Streuli $\mathrm{CH}$ : Laminin and beta1 integrins are crucial for normal mammary gland development in the mouse. Developmental Biology 1999, 215(1):13-32.

18. Fata JE, Werb Z, Bissell MJ: Regulation of mammary gland branching morphogenesis by the extracellular matrix and its remodeling enzymes. Breast Cancer Res 2004, 6(1):1-11.

19. Boudreau N, Sympson CJ, Werb Z, Bissell MJ: Suppression of ICE and apoptosis in mammary epithelial cells by extracellular matrix. Science (New York, NY) 1995, 267(5199):891-893.

20. Li N, Zhang Y, Naylor MJ, Schatzmann F, Maurer F, Wintermantel T, Schuetz G, Mueller $U$, Streuli $\mathrm{CH}$, Hynes NE: Beta1 integrins regulate mammary gland proliferation and maintain the integrity of mammary alveoli. The EMBO Journal 2005, 24(11):1942-1953.

21. Chen J, Diacovo TG, Grenache DG, Santoro SA, Zutter MM: The alpha(2) integrin subunit-deficient mouse: a multifaceted phenotype including defects of branching morphogenesis and hemostasis. Am J Pathol 2002 161(1):337-344.

22. Nagy $T$, Wei H, Shen TL, Peng X, Liang CC, Gan B, Guan JL: Mammary epithelial-specific deletion of the focal adhesion kinase gene leads to severe lobulo-alveolar hypoplasia and secretory immaturity of the murine mammary gland. The Journal of Biological Chemistry 2007, 282(43):31766-31776.

23. Faraldo MM, Deugnier MA, Tlouzeau S, Thiery JP, Glukhova MA: Perturbation of beta1-integrin function in involuting mammary gland results in premature dedifferentiation of secretory epithelial cells. $\mathrm{Mol}$ Biol Cell 2002, 13(10):3521-3531. 
24. Ali S: Prolactin receptor regulates Stat5 tyrosine phosphporylation and nuclear translocation by two separate pathways. Journal of Biological Chemistry 1998, 273(13):7709-7716.

25. Streuli CH, Edwards GM, Delcommenne M, Whitelaw CB, Burdon TG, Schindler C, Watson CJ: Stat5 as a target for regulation by extracellular matrix. The Journal of Biological Chemistry 1995, 270(37):21639-21644.

26. Xu R, Spencer VA, Bissell MJ: Extracellular matrix-regulated gene expression requires cooperation of SWI/SNF and transcription factors. The Journal of Biological Chemistry 2007, 282(20):14992-14999.

27. Wang W, Morrison B, Galbaugh T, Jose CC, Kenney N, Cutler ML: Glucocorticoid induced expression of connective tissue growth factor contributes to lactogenic differentiation of mouse mammary epithelial cells. Journal of Cellular Physiology 2008, 214:38-46.

28. Wang W, Jose C, Kenney N, Morrison B, Cutler ML: Global expression profiling reveals regulation of CTGF/CCN2 during lactogenic differentiation. J Cell Commun Signal 2009, 3(1):43-55.

29. Brigstock DR: The CCN family: a new stimulus package. J Endocrinol 2003, 178(2):169-175.

30. Perbal B: CCN proteins: multifunctional signalling regulators. Lancet 2004, 363(9402):62-64.

31. Lau LF, Lam SC: The CCN family of angiogenic regulators: the integrin connection. Experimental Cell Research 1999, 248(1):44-57.

32. Tong $Z Y$, Brigstock DR: Intrinsic biological activity of the thrombospondin structural homology repeat in connective tissue growth factor. $J$ Endocrinol 2006, 188(3):R1-8.

33. Gao R, Brigstock DR: Connective tissue growth factor (CCN2) induces adhesion of rat activated hepatic stellate cells by binding of its $\mathrm{C}$ terminal domain to integrin alpha(v)beta(3) and heparan sulfate proteoglycan. The Journal of Biological Chemistry 2004, 279(10):8848-8855.

34. Danielson K, Oborn C, Durbam E, Butel J, Medina D: Epithelial mouse mammary cell line exhibiting normal morphogenesis in vivo and functional differentiation in vitro. Proceedings of the National Academy of Sciences 1984, 81:3756-3760.

35. Hynes NE, Taverna D, Harwerth IM, Ciardiello F, Salomon DS, Yamamoto T, Groner B: Epidermal growth factor receptor, but not c-erbB-2, activation prevents lactogenic hormone induction of the beta-casein gene in mouse mammary epithelial cells. Molecular and Cellular Biology 1990, 10(8):4027-4034

36. Chammas R, Taverna D, Cella N, Santos C, Hynes NE: Laminin and tenascin assembly and expression regulate $\mathrm{HC} 11$ mouse mammary cell differentiation. Journal of Cell Science 1994, 107(Pt 4):1031-1040.

37. Cerrito MG, Galbaugh T, Wang W, Chopp T, Salomon D, Cutler ML: Dominant negative Ras enhances lactogenic hormone-induced differentiation by blocking activation of the Raf-Mek-Erk signal transduction pathway. Journal of Cellular Physiology 2004, 201(2):244-258

38. Galbaugh T, Cerrito MG, Jose CC, Cutler ML: EGF-induced activation of Akt results in mTOR-dependent p70S6 kinase phosphorylation and inhibition of HC11 cell lactogenic differentiation. BMC Cell Biol 2006, 7:34.

39. Ball RK, Friis RR, Schoenenberger CA, Doppler W, Groner B: Prolactin regulation of beta-casein gene expression and of a cytosolic 120-kd protein in a cloned mouse mammary epithelial cell line. The EMBO Journal 1988, 7(7):2089-2095.

40. Blatchford D, Hendry K, Turner M, Burgoyne R, Wilde C: Vectorial secretion by constitutive and regulated secretory pathways in mammary epithelial cells. Epithelial Cell Biology 1995, 4:5-8.

41. Humphreys R, Rosen J: Stably transfected HC11 cells provide and in vitro and in vivio model system for studying Wnt gene expression. Cell Growth and Differentiation 1997, 8:839-849.

42. Debnath J, Brugge JS: Modelling glandular epithelial cancers in threedimensional cultures. Nat Rev Cancer 2005, 5(9):675-688,

43. Gao R, Brigstock DR: Connective tissue growth factor (CCN2) in rat pancreatic stellate cell function: integrin alpha5beta1 as a novel CCN2 receptor. Gastroenterology 2005, 129(3):1019-1030.

44. Hoshijima M, Hattori $T$, Inoue $M$, Araki D, Hanagata $H$, Miyauchi $A$, Takigawa M: CT domain of CCN2/CTGF directly interacts with fibronectin and enhances cell adhesion of chondrocytes through integrin alpha5beta1. FEBS Lett 2006, 580(5):1376-1382.

45. Streuli $\mathrm{CH}$, Bailey N, Bissell MJ: Control of mammary epithelial differentiation: basement membrane induces tissue-specific gene expression in the absence of cell-cell interaction and morphological polarity. The Journal of Cell Biology 1991, 115(5):1383-1395.
46. Gao R, Brigstock DR: A novel integrin alpha5beta1 binding domain in module 4 of connective tissue growth factor (CCN2/CTGF) promotes adhesion and migration of activated pancreatic stellate cells. Gut 2006, 55(6):856-862.

47. Muschler J, Lochter A, Roskelley CD, Yurchenco P, Bissell MJ: Division of labor among the alpha6beta4 integrin, beta1 integrins, and an E3 laminin receptor to signal morphogenesis and beta-casein expression in mammary epithelial cells. Mol Biol Cell 1999, 10(9):2817-2828.

48. Prince JM, Klinowska TC, Marshman E, Lowe ET, Mayer U, Miner J, Aberdam D, Vestweber D, Gusterson B, Streuli CH: Cell-matrix interactions during development and apoptosis of the mouse mammary gland in vivo. Dev Dyn 2002, 223(4):497-516

49. Leu SJ, Liu Y, Chen N, Chen CC, Lam SC, Lau LF: Identification of a novel integrin alpha 6 beta 1 binding site in the angiogenic inducer CCN1 (CYR61). The Journal of Biological Chemistry 2003, 278(36):33801-33808.

50. Brown MC, Cary LA, Jamieson JS, Cooper JA, Turner CE: Src and FAK kinases cooperate to phosphorylate paxillin kinase linker, stimulate its focal adhesion localization, and regulate cell spreading and protrusiveness. Mol Biol Cell 2005, 16(9):4316-4328.

51. Cabodi S, Tinnirello A, Di Stefano P, Bisaro B, Ambrosino E, Castellano I, Sapino A, Arisio R, Cavallo F, Forni G, et al: p130Cas as a new regulator of mammary epithelial cell proliferation, survival, and HER2-neu oncogenedependent breast tumorigenesis. Cancer Research 2006, 66(9):4672-4680.

52. Schlaepfer DD, Broome MA, Hunter T: Fibronectin-stimulated signaling from a focal adhesion kinase-c-Src complex: involvement of the Grb2, p130cas, and Nck adaptor proteins. Molecular and Cellular Biology 1997, 17(3):1702-1713

53. Bouchard V, Demers MJ, Thibodeau S, Laquerre V, Fujita N, Tsuruo T, Beaulieu JF, Gauthier R, Vezina A, Villeneuve L, et al: Fak/Src signaling in human intestinal epithelial cell survival and anoikis: differentiation statespecific uncoupling with the PI3-K/Akt-1 and MEK/Erk pathways. Journal of Cellular Physiology 2007, 212(3):717-728.

54. Dougherty GW, Chopp T, Qi SM, Cutler ML: The Ras suppressor Rsu-1 binds to the LIM 5 domain of the adaptor protein PINCH1 and participates in adhesion-related functions. Experimental Cell Research 2005, 306(1):168-179.

55. Dougherty GW, Jose C, Gimona M, Cutler ML: The Rsu-1-PINCH1-ILK complex is regulated by Ras activation in tumor cells. Eur J Cell Biol 2008, 87(8-9):721-734.

56. Chen CC, Chen N, Lau LF: The angiogenic factors Cyr61 and connective tissue growth factor induce adhesive signaling in primary human skin fibroblasts. The Journal of Biological Chemistry 2001, 276(13):10443-10452.

57. Frazier K, Williams S, Kothapalli D, Klapper H, Grotendorst GR: Stimulation of fibroblast cell growth, matrix production, and granulation tissue formation by connective tissue growth factor. J Invest Dermatol 1996, 107(3):404-411.

58. Lin CG, Chen CC, Leu SJ, Grzeszkiewicz TM, Lau LF: Integrin-dependent functions of the angiogenic inducer NOV (CCN3): implication in wound healing. The Journal of Biological Chemistry 2005, 280(9):8229-8237.

59. Morgan MR, Humphries MJ, Bass MD: Synergistic control of cell adhesion by integrins and syndecans. Nature Reviews 2007, 8(12):957-969.

60. Chen Y, Abraham DJ, Shi-Wen X, Pearson JD, Black CM, Lyons KM, Leask A CCN2 (connective tissue growth factor) promotes fibroblast adhesion to fibronectin. Mol Biol Cell 2004, 15(12):5635-5646.

61. Kennedy L, Liu S, Shi-Wen X, Chen Y, Eastwood M, Sabetkar M, Carter DE, Lyons KM, Black CM, Abraham DJ, et al: CCN2 is necessary for the function of mouse embryonic fibroblasts. Experimental Cell Research 2007, 313(5):952-964.

62. Klinowska TC, Alexander CM, Georges-Labouesse E, Neut Van der R, Kreidberg JA, Jones CJ, Sonnenberg A, Streuli CH: Epithelial development and differentiation in the mammary gland is not dependent on alpha 3 or alpha 6 integrin subunits. Developmental Biology 2001, 233(2):449-467.

63. Faraldo MM, Deugnier MA, Thiery JP, Glukhova MA: Growth defects induced by perturbation of beta1-integrin function in the mammary gland epithelium result from a lack of MAPK activation via the Shc and Akt pathways. EMBO Rep 2001, 2(5):431-437.

64. Watkin H, Richert MM, Lewis A, Terrell K, McManaman JP, Anderson SM: Lactation failure in Src knockout mice is due to impaired secretory activation. BMC Dev Biol 2008, 8:6.

doi:10.1186/1471-2121-11-35

Cite this article as: Morrison et al: Connective Tissue Growth Factor (CTGF/CCN2) enhances lactogenic differentiation of mammary epithelial cells via integrin-mediated cell adhesion. BMC Cell Biology 2010 11:35. 